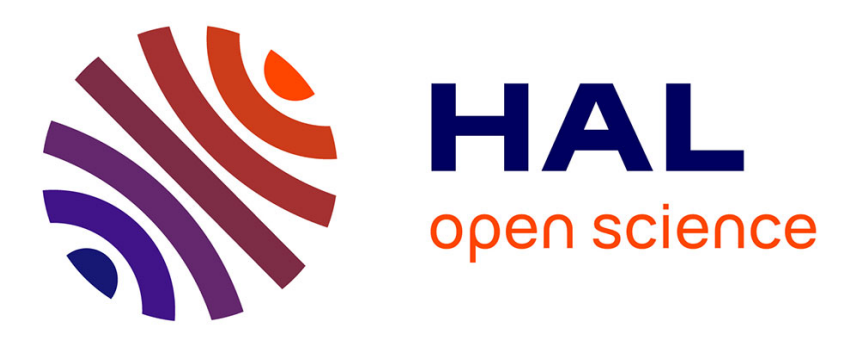

\title{
Cricket calling communities as an indicator of the invasive ant Wasmannia auropunctata in an insular biodiversity hotspot
}

\author{
A. Gasc, J. Anso, J. Sueur, Herve Jourdan, L. Desutter-Grandcolas
}

\section{To cite this version:}

A. Gasc, J. Anso, J. Sueur, Herve Jourdan, L. Desutter-Grandcolas. Cricket calling communities as an indicator of the invasive ant Wasmannia auropunctata in an insular biodiversity hotspot. Biological Invasions, 2018, 20 (5), pp.1099-1111. 10.1007/s10530-017-1612-0 . hal-01704447

\section{HAL Id: hal-01704447 \\ https://hal.science/hal-01704447}

Submitted on 21 May 2018

HAL is a multi-disciplinary open access archive for the deposit and dissemination of scientific research documents, whether they are published or not. The documents may come from teaching and research institutions in France or abroad, or from public or private research centers.
L'archive ouverte pluridisciplinaire $\mathbf{H A L}$, est destinée au dépôt et à la diffusion de documents scientifiques de niveau recherche, publiés ou non, émanant des établissements d'enseignement et de recherche français ou étrangers, des laboratoires publics ou privés. 


\title{
Cricket calling communities as an indicator of the invasive ant Wasmannia auropunctata in an insular biodiversity hotspot
}

\author{
A. Gasc ·J. Anso - J. Sueur • H. Jourdan - L. Desutter-Grandcolas
}

\begin{abstract}
Invasive species are a major concern for the maintenance of ecosystem services and biodiversity but are difficult to mitigate. Upstream solutions to prevent their impact, including their detection, are needed. Wasmannia auropunctata, an invasive ant living in vagile supercolonies, is especially hard to track and is a major threat for tropical ecosystems and local animal communities. As part of such tropical communities, crickets are sensitive to ecological conditions, easy to collect, detectable and identifiable
\end{abstract}

\author{
A. Gasc \\ Department of Forestry and Natural Resources, Center for \\ Global Soundscapes, Purdue University, 203 South Martin \\ Jischke Drive, B066 Mann Hall, West Lafayette, \\ IN 47907, USA \\ e-mail: amandine.gasc@gmail.com \\ J. Anso $\cdot$ H. Jourdan \\ Institut Méditerranéen de Biodiversité et d'Écologie \\ marine et continentale (IMBE), UMR 7263 CNRS, IRD \\ 237, Centre IRD Nouméa, Aix-Marseille Université, \\ Avignon Université, BP A5, 98848 Nouméa Cedex, \\ Nouvelle-Calédonie
}

A. Gasc · J. Sueur - L. Desutter-Grandcolas Institut de Systématique, Evolution, Biodiversité (ISEB), UMR 7205 CNRS, MNHN, UMPC, EPHE, Muséum national d'Histoire naturelle, Sorbonne Universités, 57 rue Cuvier, CP 50, 75005 Paris Cedex 05, France through their species-specific calls. Here, we evaluated the use of an acoustic community of crickets as an indicator of the presence of W. auropunctata in New Caledonia. We evaluated the dominance of the crickets in the soundscape, describe the cricket community structure and diversity along a shrubland to forest gradient, characterize these cricket communities structure and diversity in the light of ongoing invasion by $W$. auropunctata, and identify cricket species' indicators of the invasion. Acoustic recordings collected on 24 sites were described using humanlistening and spectrographic visualization. The results demonstrated a clear dominance of the cricket group in the New Caledonian nocturnal soundscapes. Each habitat harbored a specific acoustic cricket community related to specific environmental attributes including vegetation height, daily variation of humidity and temperature. The presence of $W$. auropunctata was significantly associated with a lower cricket acoustic activity and species richness at night. Of the 19 species detected, four nocturnal species were identified as indicator of non-invaded forests and preforests. This work supports the use of acoustic as an alternative method to detect invasion.

Keywords Bioindicator - Acoustic community · Invasive species $\cdot$ Soundscape $\cdot$ Ecoacoustics 


\section{Introduction}

Biological invasion is one of the major drivers of ongoing global environmental change (Vitousek et al. 1996; Simberloff et al. 2013). Because negative impacts of invasive alien species on ecosystem services, community structure, and biodiversity are important and difficult to mitigate, upstream solutions to prevent impact of invasive species are needed (Hulme 2006; Ehrenfeld 2010; Simberloff et al. 2013). Among invasive species, ants receive specific attention due to their demonstrated association with ecosystem function and biodiversity loss (Lach and Hooper-Bui 2010). Invasion success of this group resides in their low intra-species aggression (unicoloniality), high inter-species aggression, mutualism behavior, and high competition for local resources with native species (Holway 1998; Holway et al. 2002). Environmental managers need efficient tools to detect their presence, evaluate their impacts, and track their spread to initiate management action as early as possible (Hulme 2006). In this context, invasive ants that are small and live in mobile colonies are especially hard to track.

Recent advances in ecoacoustics contributed to the idea of using sound from the activity of an animal community as an indicator of environmental conditions or ecological changes (Pijanowski et al. 2011; Sueur and Farina 2015). In both terrestrial and aquatic environments, many animal species rely on acoustic signals to interact. Species acoustically active in a given space and at a specific time constitute an acoustic community contributing to the soundscape. The term soundscape here is defined as the "physical extent of acoustic signals and the spectral range of signal frequencies associated with an ecosystem's biophysical processes" following Qi et al. (2008). Acoustics of animal communities can reflect their diversity, composition and dynamics and be indicative of environmental trends (Gasc et al. 2013; Lellouch et al. 2014; Towsey et al. 2014). Several studies have linked the acoustic profile of animal communities with habitat characteristics and/or human disturbances (Sueur et al. 2008; Joo et al. 2011; Tucker et al. 2014). Based on these promising results, the direct influence of biological invasion on acoustic communities in the natural environment needs to be investigated (Boelman et al. 2007).
Among soniferous insects, crickets (Orthoptera, Grylloidea) possess several of the required qualities to potentially be bioacoustic indicators in the tropics: (1) crickets are widely distributed in the tropics with reasonably high overall abundance and wide local diversity (Otte and Alexander 1983; Otte 1994; Desutter-Grandcolas et al. 2016), (2) many cricket species rely on acoustic signals to attract a mate, and their calls are most often species-specific and easy to identify (Riede 1997; Diwakar and Balakrishnan 2007), (3) convincing evidence placed crickets as sensitive to environmental changes, including ecological succession (Desutter-Grandcolas 1992; Szinwelski et al. 2012) and biological invasion (LaPolla et al. 2000). In this context, the survey of the acoustic community of crickets could represent a fast and efficient approach for habitat surveys in general and for the detection of invasive species in particular.

To test this hypothesis, we conducted an acoustic survey of the abundant, diverse and well-described cricket communities in New Caledonia (Anso 2016; Anso et al. 2016b). New Caledonia is a Pacific archipelago, considered a major biodiversity hotspot that is threatened by human activity and invasive species (Myers et al. 2000). Among invasive ants, Wasmannia auropunctata (Roger 1863) appears as one of the "six most widespread, abundant, and damaging invasive ants" in the world (Holway et al. 2002) and one of the "100 world's worst invasive species" (Lowe et al. 2000). This species spreads and impacts biodiversity in all New Caledonian habitats (Jourdan et al. 2001; Le Breton et al. 2003; Berman et al. 2013). For this survey, we selected 24 sites in the south of the main island according to two critical ecological conditions: the habitat type and the presence $W$. auropunctata. We passively recorded and analyzed soundscapes from these sites to evaluate the dominance of the cricket group in the overall acoustic community, described the structure and diversity of the calling cricket communities in three dominant habitats, and characterized the response of cricket calling communities to the ongoing invasion by $W$. auropunctata on the cricket calling communities. 


\section{Methods}

Study sites

Selected sites were on similar metalliferous soil in southern New Caledonia, hosting three main habitat types following a vegetation gradient: "forest", "preforest" and "shrubland" (Online Resource 1). We selected invaded and non-invaded sites leading to a total of six modalities ( 3 habitat types $\times 2$ invasion conditions). Each modality was replicated four times for a total of 24 sites (Online Resource 2). Sites were reported as invaded and non-invaded by researchers of the Institute of Research and Development of Noumea. To characterize the invasion by $W$. auropunctata on these sites, we established two perpendicular transects of $200 \mathrm{~m}$ oriented North-South and East-West in each site, centered on the acoustic sensor. We investigated the presence/absence of $W$. auropunctata during $5 \mathrm{~min}$ at the sensor location and at $50 \mathrm{~m}$ and $100 \mathrm{~m}$ from the recorder along the transects. 'Non-invaded' sites were associated with more than $85 \%$ of the check-points free of the invasive, and 'invaded' sites were associated with more than $85 \%$ check-points where the invasive was found. This evaluation was conducted just before the acoustic sampling. All sites were at $189 \mathrm{~m}$ (SD 83) elevation above sea level and separated by at least $200 \mathrm{~m}$.

\section{Acoustic recording procedure}

We collected recordings during the dry season, from 17 October to 26 December 2013 with automatic field recorders, SongMeter SM2 and SM2 + (Wildlife Acoustics, Concord, NY, U.S.A.), that have similar technical specifications for each modality (Online Resource 2). We deployed one recorder on each site. We equipped each acoustic sensor with two omnidirectional microphones (frequency response: - 35 Decibels (SD 4) between 20 Hertz and 20,000 Hertz) oriented horizontally, one at $1.5 \mathrm{~m}$ and the other at $30 \mathrm{~cm}$ from the ground. We set the gain to +36 Decibels and the sampling frequency rate at 48,000 Hertz (16 bits). We configured the acoustic sensors to record 2 min every $58 \mathrm{~min}$. We first stored the files in the lossless compression format.wac and then transformed them into.wav with the software Kaleidoscope version 1.1.20. The files were examined $(n=20,512)$ to discard those $(\mathrm{n}=3056)$ containing anthropogenic noise (e.g. human voices), rain and/or wind.

Calling identification and count

For each site, we selected 120 recordings, corresponding to the beginning of every hour-from 07:00 to 16:00 $\mathrm{h}$ and from 19:00 to 04:00 $\mathrm{h}$-for 6 days randomly selected. We deliberately discarded dusk and dawn choruses, at 05:00 and 06:00 $\mathrm{h}$ and at 17:00 and 18:00 h, because of the dominance of overlapping bird sounds. We simultaneously listened and visualized the selected recordings using a spectrogram generated with Audacity (non-overlapping 1024 sample Blackman-Harris window), for a more accurate discrimination of call overlaps (Truskinger et al. 2013). First, we classified calls-defined here as a distinct acoustic production-in four main acoustic groups as follow: birds, crickets, katydids and others (cicadas, anurans, cats and bats). Then, we identified the cricket calls at a species level and counted the number of calls per species (Online Resource 3), based on taxonomic and acoustic descriptions published by Anso et al. (2016b).

Environmental variables

At each site, we delimited a plot of 10 square meters where we characterized the vegetation and the climatic attributes. We assessed bare ground and vegetation layers (herbaceous, shrubs, canopy) visually from the center of each plot. We counted trunks with a diameter at breast height (dbh) above $30 \mathrm{~cm}$ and assessed plant species richness by sight with help from a local botanist. We assessed canopy closure in the middle and four corners of each plot by evaluating the percentage of light in the forest over story with a $180^{\circ}$ hemispherical lens and the Gap Light Analyzer software 2.0 (Frazer et al. 1999). We recorded climatic attributes including daily temperature (in ${ }^{\circ} \mathrm{C}$ ) and relative humidity (in \%) every 5 min using a waterproof thermo-hygrometer sensor (HOBO U23 Pro v2) attached to a tree $(0.7 \mathrm{~m})$ near the acoustic sensors. Daily variations in humidity and temperature corresponded to the difference between highest and lowest value for each parameter for each day. 


\section{Analyses}

Analyses performed on the entire day (defined as all hours except the two chorus periods) are referred as '24-h' analyses. Analyses that focused on two time periods of the day, from 07:00 to $16: 00 \mathrm{~h}$ and from 19:00 to $04: 00 \mathrm{~h}$, are respectively referred as 'daytime' and 'nighttime' analyses.

\section{Non-invaded sites}

To evaluate the dominance of the crickets in the New Caledonian soundscape, we calculated the percentage of occurrence-defined here as the total number of calls counted through the entire set of recordings-for each taxonomic group (crickets, katydids, birds and others) in the three selected habitats. This calculation was done separately for daytime and nighttime periods.

To assess the efficiency of the recording effort to describe the calling cricket community, we computed a species richness accumulation curve, which is the cumulative number of aurally identified species as a function of the cumulative recording number. As cricket communities are expected to vary depending on environmental conditions, we computed one curve for each habitat and for both 'daytime' and 'nighttime' periods. We computed these curves by considering the average value of species richness-values averaged among the four sites corresponding to the replication of the same habitat type. We followed the samplebased rarefaction method (Chiarucci et al. 2008). These curves were obtained with the function 'specaccum' available in the $\mathrm{R}$ package vegan version 2.2-1 (Oksanen et al. 2013).

To investigate the differences in cricket calling community structure between the types of habitat, and to investigate the possible relationship between environmental variables and the specificity of cricket community for each habitat, we performed a Nonmetric Multidimensional Scaling (NMDS) with BrayCurtis distances (Minchin 1987; Legendre and Legendre 2012). First, we calculated the distance between sampling sites based on the presence/absence data of cricket species identified from the 24 -h period recordings (Minchin 1987). As recommended by Baselga (2008) to interpret the results, we set the stress value of the NMDS to 0.1 (random iteration $=1000$, dimension $=2$ ). Then, sampling sites were plotted together according to habitat type. Environmental variables were fitted into ordination, and correlated with the species matrix with permutation test (random iteration $=999, p<0.05)$. We performed an analysis of similarities (ANOSIM) to test for significant differences in community composition with habitat type as explaining factor, also using a permutation test (type I error rate at 5\%). NMDS was performed using the function 'metaMDS' from the $\mathrm{R}$ package vegan (Oksanen et al. 2013). Environmental variables were fitted into ordination using the 'envfit' function from the same package.

\section{Non-invaded and invaded sites}

To evaluate the effect of $W$. auropunctata on the acoustic diversity of the cricket communities, we calculated the species richness (number of species identified) and the total number of calls counted by listening for each recording. Then, we computed a Generalized Linear Mixed Model (GLMM; Bolker et al. 2009) including the independent variables 'invasion' and 'habitat', considered as fixed effects, and the independent variables 'site', 'time', and 'date' considered as random effects (random intercept). The dependent variable was species richness for the model 1 and number of calls for the model 2, both fitted with a Poisson distribution with a log link function adapted for count data (Bolker et al. 2009). We ran these models separately on data collected during the nighttime and daytime periods using the function 'glmer' from the $\mathrm{R}$ packages lme4 (Bates et al. 2015). Validation steps for the models were not sufficient for the daytime data, but were sufficient for the nighttime period (Online Resource 4). Consequently, we only interpreted the results of the nighttime models. For both models, we obtained the $p$ values of the effect of 'invasion' factor on, respectively, the number of species and the number of calls, by computing likelihood ratio tests of the full model and the model without the fixed effect 'invasion' (Bolker et al. 2009; type I error rate at 5\%). As proposed by Nakagawa and Schielzeth (2013), we computed the marginal and conditional $\mathrm{R}^{2}$ following the method adapted for GLMM with Poisson errors with Log link function.

To evaluate if the cricket community composition is singular under the invasion, we performed NMDS and ANOSIM analyses following the procedure 
previously described. We conducted these analyses considering first the presence/absence of the cricket species and then the abundance of calls per species from non-invaded and invaded sites during $24 \mathrm{~h}$. We excluded one invaded shrubland site from these analyses because of the absence of any species in the community and was therefore treated as an outlier in the analysis. The test of similarities ANOSIM were performed within each habitat, with the invasion as explanatory factor.

To identify species indicating the presence of $W$. auropunctata, we conducted indicator species analysis for each habitat independently and during $24 \mathrm{~h}$ (Dufrêne and Legendre 1997; De Cáceres et al. 2010). We calculated the non-equalized indicator species values and evaluated its significance by applying a permutation test $(n=1000$ permutations; type I error rate at 5\%) as suggested by De Cáceres and Legendre (2009) (similar results are observed with equalized indicator species values). We ran two sets of analyses separately, first using the presence/absence of the cricket species and then second using the abundance of calls per cricket species. Indicator species analyses were performed using the function 'mutlipatt' from the R package indicspecies (De Cáceres and Legendre 2009).

\section{Results}

Overall, the occurrence of species acoustically detected through 24-h analysis among the three habitats placed crickets as the dominant acoustic group $(59.5 \%)$. Birds were the second acoustic group (31\%), followed by katydids $(7.9 \%)$. Different patterns of dominance between daytime and nighttime could be identified (Fig. 1). During the day, birds were the main acoustic group (58.8\%), followed by crickets $(34.1 \%)$ and katydids (5.6\%). Considering the three habitat types, occurrence of cricket calls during the daytime accounted for $40.5 \%$ in 'forest', $25 \%$ in 'preforest' and $37.2 \%$ in 'shrubland'. Nocturnal cricket species largely dominated the nighttime soundscapes $(85 \%)$, followed by katydids $(10.1 \%)$ and birds $(3.3 \%)$. Considering the three habitat types, occurrence of cricket calls during the nighttime accounted for $85.2 \%$ in 'forest', $73.4 \%$ in 'preforest' and $96.4 \%$ in 'shrubland'.

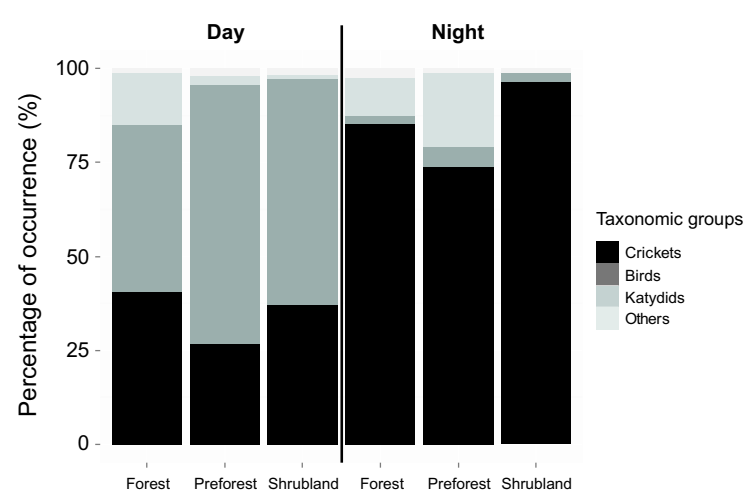

Fig. 1 Percentage of occurrence of calls in audio recordings for each acoustic group. The sample size for each habitat and time period is of 240 recordings

Species accumulation curves reached an asymptote over the period analyzed around three days of recordings, suggesting that acoustic communities have been almost completely sampled (Fig. 2). Considering the nighttime period, 'preforest' held the highest species richness with 10 species, followed by 'forest' with nine species, and 'shrubland' with five species. For the daytime period, the species accumulation curves followed the same pattern as during the nighttime period: 'preforest' held the highest species accumulation of acoustic species (six species), followed by 'forest' (five species) and 'shrubland' (three species).

From the recordings, a total of 19 cricket species were identified belonging to four families as defined by Chintauan-Marquier et al. (2016), i.e. Mogoplistidae with four species, Trigonidiidae with six species, Phalangopsidae with one species and Gryllidae with eight species. Among these 19 species, 10 were identified during daytime, and 16 during nighttime recordings (Table 1). Five out of 12 species were exclusively found in the forest, three out of 13 species in the preforest and one out of five species in the shrubland. Forest and preforest shared six species, preforest and shrubland shared three, and only one species, Calcirtus magnus, was found in the three habitats (Table 1).

NMDS ordination in two dimensions showed a clear effect of habitat type on acoustic communities (Fig. 3). Each habitat was fully discriminated with no overlap and supported by robust analysis of similarities (ANOSIM $\mathrm{R}^{2} 0.94, p<0.001$ ). The ordination was significantly explained by 12 environmental and bioclimatic variables that are: herbaceous layer, tree 
Fig. 2 Species accumulation curves for cricket species in forest, preforest and shrubland. Gray areas indicate standard deviation
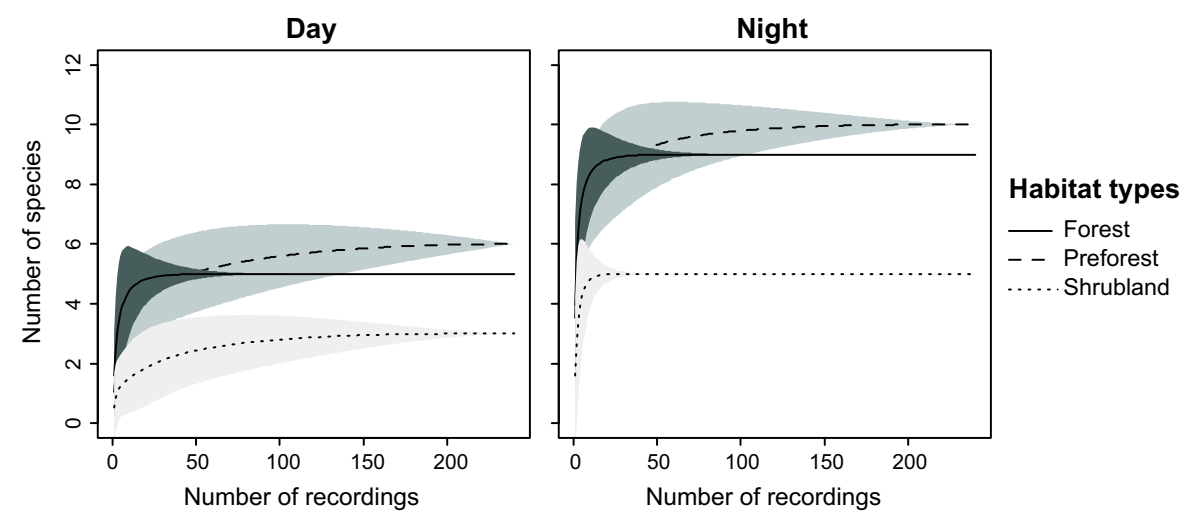

Table 1 Information related to species identified in the recordings with calling sites inferred from microhabitat of the species described. Reproduced with permission from Anso et al. (2016b)

\begin{tabular}{|c|c|c|c|c|}
\hline Family & Species & Habitat & Diel calling & Calling sites \\
\hline Gryllidae & Agnotecous meridionalis $^{\mathrm{a}, \mathrm{d}}$ & Forest & Night & Leaf litter \\
\hline Gryllidae & Agnotecous azurensis & Forest/preforest & Day/Night & Leaf litter \\
\hline Gryllidae & 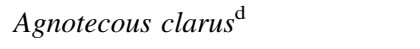 & Forest/preforest & Night & Leaf litter \\
\hline Gryllidae & Archenopterus bouensis & Forest/preforest & Night & Canopy \\
\hline Gryllidae & Calscirtus magnus & Forest/preforest/shrubland & Night & Canopy \\
\hline Gryllidae & Notosciobia affinis paranola & Forest/preforest & Day/Night & Leaf litter \\
\hline Gryllidae & Notosciobia minoris $^{\mathrm{e}}$ & Forest/preforest & Night & Leaf litter \\
\hline Gryllidae & Notosciobia $\mathrm{sp} 1^{\mathrm{b}, \mathrm{d}}$ & Preforest & Night & Leaf litter \\
\hline Trigonidiidae & Bullita fusca $^{\mathrm{d}}$ & Forest/preforest & Day & Leaf litter \\
\hline Trigonidiidae & Bullita mouirangensis ${ }^{\mathrm{a}, \mathrm{d}}$ & Forest & Day & Leaf litter \\
\hline Trigonidiidae & Bullita obscura ${ }^{\mathrm{b}, \mathrm{d}}$ & Preforest & Day/Night & Leaf litter \\
\hline Trigonidiidae & Koghiella flammea & Preforest/Shrubland & Day/Night & Leaf litter \\
\hline Trigonidiidae & Koghiella nigris $^{\mathrm{a}}$ & Forest & Day/Night & Bare soil \\
\hline Trigonidiidae & Trigonidiinae $\mathrm{sp}^{\mathrm{b}}$ & Preforest & Day & Understory \\
\hline Mogoplistidae & Mogoplistidae sp1 & Preforest/Shrubland & Night & Low veg. \\
\hline Mogoplistidae & Mogoplistidae sp2 & Preforest/Shrubland & Day/Night & Low veg. \\
\hline Mogoplistidae & Mogoplistidae $\mathrm{sp}^{\mathrm{c}, \mathrm{d}}$ & Shrubland & Day/Night & Leaf litter \\
\hline Mogoplistidae & Mogoplistidae $\mathrm{sp}^{\mathrm{a}}$ & Forest & Night & Low veg. \\
\hline Phalangopsidae & Pseudotrigonidium caledonica ${ }^{\mathrm{a}, \mathrm{d}}$ & Forest & Night & Understory \\
\hline
\end{tabular}

"veg." calls for vegetation

${ }^{\text {a }}$ Species unique to forest

${ }^{\mathrm{b}}$ Species unique to preforest

${ }^{\mathrm{c}}$ Species unique to maquis

${ }^{\mathrm{d}}$ Species absent in invaded area

${ }^{\text {e}}$ Species only present in invaded area

layer, bare ground, vegetation height, stem diameter, canopy closure, mean temperature, high temperature, daily temperature variation, mean humidity, lowest humidity, and daily humidity variation.
A total of eight species recorded in non-invaded habitats were absent in invaded areas (Pseudotrigonidium caledonica, Agnotecous meridionalis, A. clarus, Bullita mouirangensis, B. obscura, Mogoplistidae sp3 


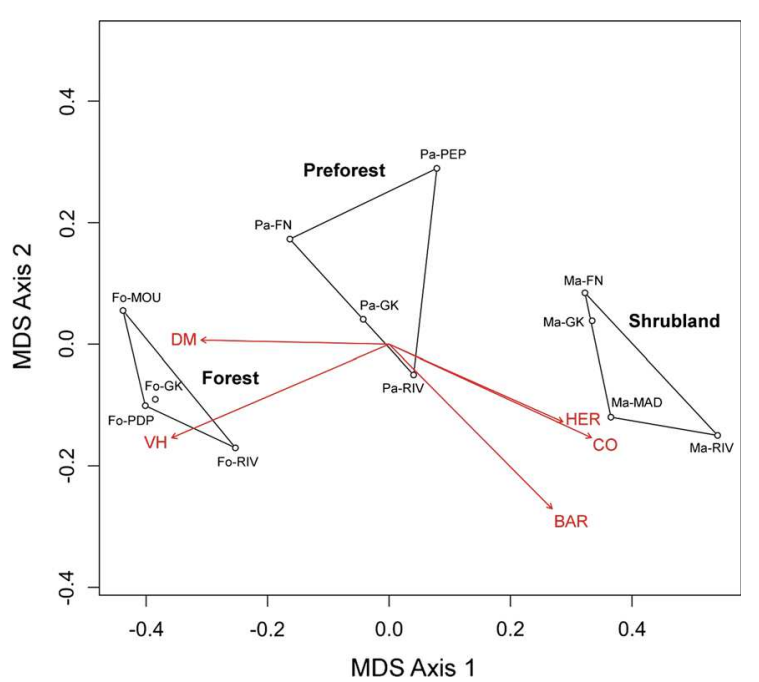

Fig. 3 NMDS (stress $=0.04$, two dimensions) based on presence and absence of cricket species based on call identifications and environmental parameters. Twelve significant environmental variables are shown (ENVFIT, $\mathrm{p}<0.05$ with 999 permutations). Points represent the sites $(n=4$ replicates per habitat type) and each of their site ID for the survey. Polygons were drawn according to habitat type. Sites, such as FO-PDP, are labeled according to the habitat type (FO for forest, PA for preforest and MA for shrubland) and then according to the locality name (see Table S1 for additional information). Abbreviations: 'HER' for 'Herbaceous layer', 'TRE' for 'Tree layer', 'BAR' for 'Bare ground', 'VH' for 'Vegetation height', 'DM' for 'DBH of stems', 'CO' for Canopy openness, 'MT' for 'Mean temperature', 'HT' for Highest temperature, 'DT' for Daily temperature variation, ' $\mathrm{MH}$ ' for Mean humidity, 'LH' for Lowest humidity, 'DH' for Daily humidity variation

and Notosciobia sp1). By contrast, one species, Notosciobia minoris, was only recorded in invaded habitats (Table 1). A total of eight species were recorded in both invaded and non-invaded habitats: Agnotecous azurensis, Koghiella flammea, K. nigris, Trigonidiinae sp, Mogoplistidae sp1, Mogoplistidae sp2, Notosciobia affinis paranola, of which all were associated with a lower number of calls in presence of W. auropunctata (reduction of $76.17 \%$ (SD 19.81) of total calls observed per species) and Mogoplistidae sp7 showing no clear difference in total of calls observed between the two conditions (Online Resource 3).

The number of cricket species and calls observed in the recordings show lower values in invaded than in non-invaded area in all three habitat types (Fig. 4). The GLMM models explained 62.1 and $86 \%\left(\mathrm{R}^{2} \mathrm{c}\right.$ values) of the variability of the number of species and the number of calls in nighttime recordings respectively. These models showed a significant impact of the invasion by $W$. auropunctata on both the number of species and the number of calls observed in the nighttime recordings. The average number of species in sites without $W$. auropunctata was equal to the exponential intercept of the model 1 (4.32) and the average number of species in sites with $W$. auropunctata to the exponential of the intercept of the model added to the estimate of the factor level 'with W. auropunctata' (1.08) leading to a significant average difference of 3.24 species per recordings in presence of the invasive ant (likelihood ratio test: $\left.\chi^{2}(1)=16.39, p=5.17 \mathrm{e}-05\right)$. Similarly, the results of model 2 showed that the average number of calls in sites without $W$. auropunctata (110.79), and the average number of calls in sites with $W$. auropunctata (20.47) lead to a significant average difference of 90.32 calls per recordings between the two conditions (likelihood ratio test: $\chi^{2}(1)=8.33, p=0.004$ ).

Both NMDS ordinations in two dimensions-based on the presence/absence of the species and based on the calling song abundance of cricket species - showed that particular cricket species communities exist in the presence of $W$. auropunctata in forest and preforest with few or no overlaps. However, there is a large overlap of cricket communities from invaded and non-invaded shrublands (Fig. 5). Analysis of similarities (ANOSIM) supports this observation with significant dissimilarity in cricket community composition in forest using presence/ absence of cricket species $\left(\mathrm{R}^{2}=0.43 p=0.031\right)$ and abundance of calls per cricket species $\left(\mathrm{R}^{2}=0.51\right.$, $p=0.034)$, significant results in preforest using presence/absence of cricket species $\left(\mathrm{R}^{2}=0.62, p=0.037\right)$ and abundance of calls per cricket species $\left(\mathrm{R}^{2}=0.4\right.$, $p=0.033$ ), and non-significant results in shrubland using both presence/absence of cricket species $\left(\mathrm{R}^{2}=0.51, p=0.059\right)$ and abundance of calls per cricket species $\left(\mathrm{R}^{2}=0.3, p=0.081\right)$.

Results of the indicator species analysis identified the cricket species A. azurensis and A. bouensis ( $p=0.022)$ as significant indicators of the ant invasion in forest, and A. clarus, Mogoplistidae. sp1 and Mogoplistidae $\operatorname{sp} 2(p=0.033)$ in preforest. No species has been identified as indicator of the ant invasion in shrubland. Indicator species analyses conducted using the presence/absence data only identified A. clarus $(p=0.032)$ in preforest habitat, highlighting the importance of collecting the abundance of calls per species in this survey. 

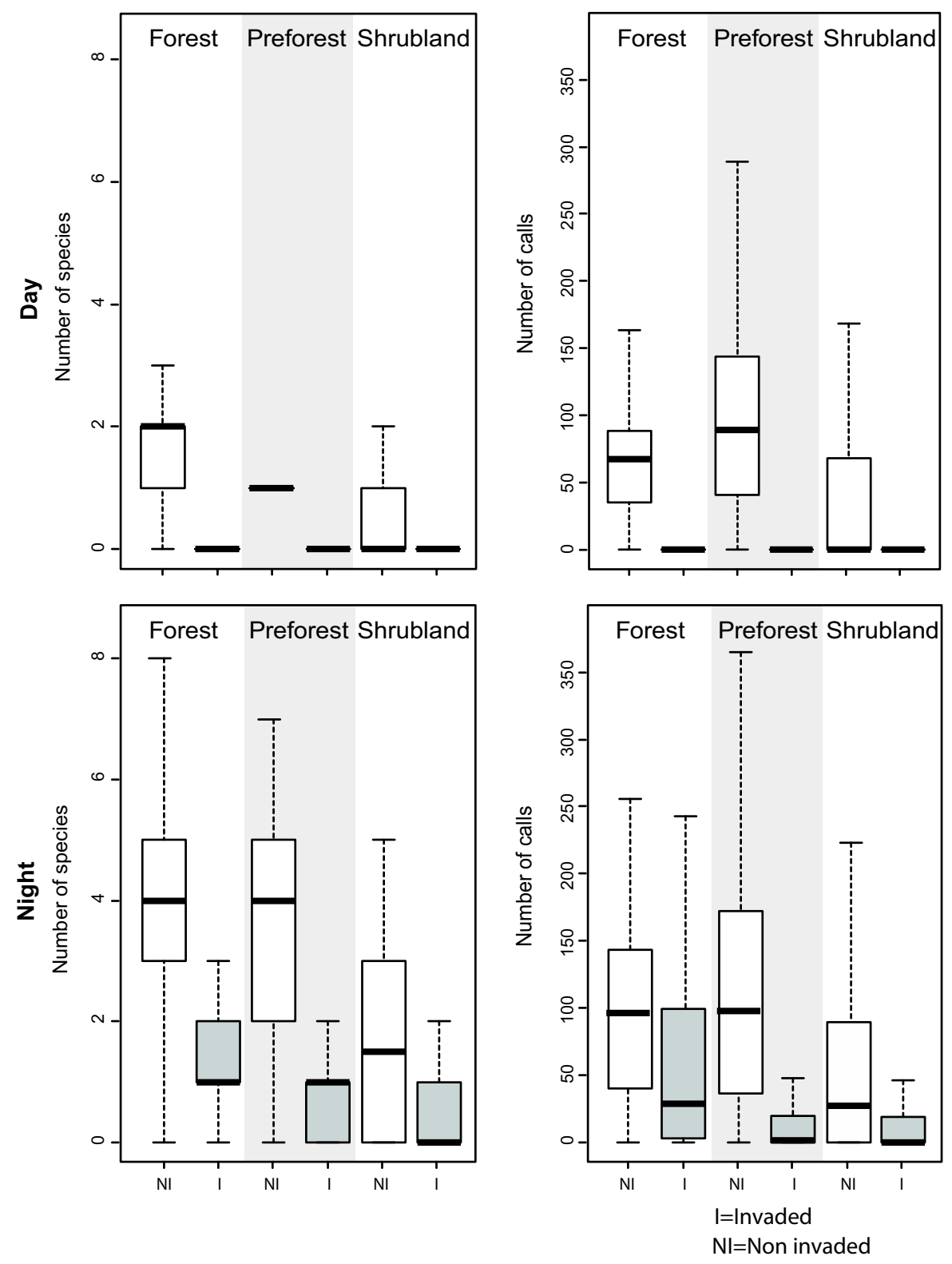

Fig. 4 Boxplots representing the number of cricket species and calls for each habitat and invaded modalities. The middle band inside the box represents the median value, the bottom and top of the box respectively the first $(\mathrm{Q} 1)$ and third $(\mathrm{Q} 3)$ quartiles and, the whiskers extend to points that lie within Q1 $-1.5 * \mathrm{IQR}$ and

\section{Discussion}

Ecoacoustic approaches that consist, among others, in recording and analyzing acoustic communities and soundscapes, offer applications for habitat surveys. Five arguments supporting the use of the cricket

$\mathrm{Q} 3+1.5 * \mathrm{IQR}$, IQR being the interquartile range between $\mathrm{Q} 1$ and Q3. Forest, preforest and shrubland free from invasive species are in blank plots, while invaded habitats by Wasmannia auropunctata are in gray plots, for daytime and nighttime periods

calling community as an indicator of the invasive ant, W. auropunctata, in New Caledonia are discussed.

First, research is establishing a solid referential knowledge of these cricket communities. From an effort devoted to the taxonomy and systematics of New Caledonia initiated 30 years ago, crickets have 


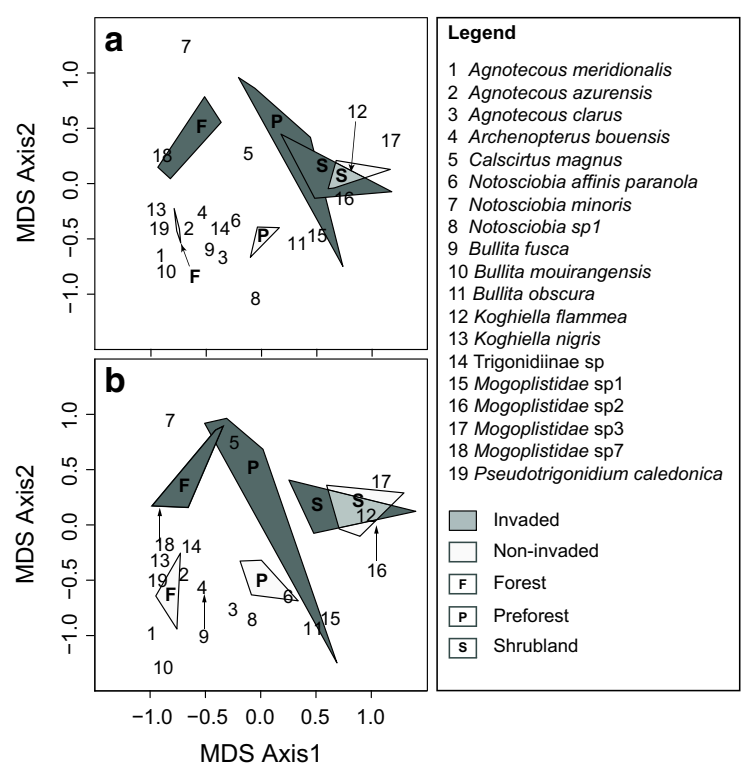

Fig. 5 NMDS (two dimensions) based on a-the presence and absence of cricket species acoustically identified (stress $=0.11$ ) and b-the abundance of calls per cricket species (stress $=0.1$ ). Polygons were drawn according to habitat type and ant invasion. Sites, such as FO-PDP, are labeled according to the habitat type (FO for forest, PA for preforest and MA for shrubland) and then according to the locality name (see Table S1 for additional information). The site MA-KA-W has been excluded from this analysis

been rapidly identified as one of the main putative model groups, with studies devoted to acoustic evolution (Robillard et al. 2007; Anso et al. 2016a), speciation (Nattier et al. 2012), and more recently, the succession of cricket communities in different habitats (Anso 2016). The results presented here are considered in the context of complementary taxonomic, ecological and acoustic knowledge acquisition of this group in New Caledonia (Anso 2016; Anso et al. 2016b; Desutter-Grandcolas et al. 2016).

Second, the abundance and dominance of detectable cricket calls in nighttime soundscapes has been demonstrated. Using soundscape descriptions, we could ascertain the presence of 19 of the 29 overall cricket species - both mute and acoustically activedescribed by complementary classic inventories made on the same site (Anso et al. 2016b). The cricket stridulations largely dominate the nighttime soundscapes, justifying the acoustic approach to detect environmental changes through the nocturnal acoustic activities of cricket communities. While cricket communities are known to be abundant in all tropical systems (Riede 1993; Nischk and Riede 2001), their dominance in all tropical nighttime soundscapes still needs to be demonstrated in order to generalize this approach to other sites and other invasion contexts.

Third, the three habitat types were successfully discriminated by the acoustic signature of their cricket communities. From taxonomical inventories made on the same sites (Anso 2016; Anso et al. 2016b), we know that the entire cricket community (species producing or not producing calls) are habitat specific. Although the acoustic approach allows the detection of only a subset of the overall cricket community, the results of our acoustic study confirm that the acousticmediated species of the cricket community are sensitive to different environmental conditions (DesutterGrandcolas 1992; Szinwelski et al. 2012), and that each habitat can be defined by a specific acoustic signature as shown in Bormpoudakis et al. (2013). More specifically, some cricket species have been recorded only in one habitat type, as documented for other Orthoptera in European/temperate countries (Schirmel et al. 2011; Fartmann et al. 2012). This suggests that the ecological distribution of cricket species may be restricted by particular microclimatic conditions (Gardiner and Dover 2008), environmental constraints for communication (Römer 1993), and/or micro-habitat availability (Jain and Balakrishnan 2011).

Fourth, results showed the significant effect of the presence of $W$. auropunctata on cricket acoustic activity in all habitats and on cricket community composition in forest and preforest habitat. These results could be supported by four different hypotheses: (1) a reduction in species number in the community, (2) a reduction in the number of individuals per species, (3) a targeted effect on some cricket species and/or (4) a change in the behavior of the species in the presence of the ant, leading to a decrease in acoustic activity. To the best of our knowledge, no survey has investigated the effects of invasive ants on any calling behavior. However, the spread of $W$. auropunctata generally negatively affects terrestrial invertebrates (Lubin 1984; Jourdan et al. 2001; Walker 2006). Complementary classic species inventory documented that the presence of the ant decreased both the number of individuals and the number of cricket species at the sites (Anso 2016). Two non-exclusive mechanisms could explain this decrease in species and individuals detected through acoustic activity. First, non-lethal 
interactions by indirect competition for calling sites, shelter or food resources, or by territorial defensive attacks-W. auropunctata uses a poisonous stinger to repeal predators-could lead crickets to move and avoid the invaded area. A second mechanism could be lethal interactions by direct predation of the ant on eggs or small individuals, including juveniles. Interestingly, among the species not recorded in the invaded area, seven species were leaf litter-dwellers, suggesting a higher sensitivity to foraging ant workers than crickets perched on vegetation. In the same way, Pseudotrigonidium caledonica, a discrete forest species that perched on understory vegetation for calling, but may hide during the day in the leaf litter accumulated at the base of the plants, was not recorded in invaded areas. This pattern likely highlights the vulnerability of $P$. caledonica to $W$. auropunctata, perhaps during other activities, such as feeding, resting or copulating. According to our findings, four cricket species could be defined as acoustic flags revealing the presence of $W$. auropunctata: A. azurensis (daytime and nighttime) in forest; A. clarus (nighttime), Mogoplistidae sp1 and Mogoplistidae sp2 (nighttime) in preforest. However, we suspect other potential indicator species from our personal observations such as B. mouirangensis (daytime), $P$. caledonica (nighttime) and A. meridionalis (nighttime) in forests, B. fusca (daytime) and B. obscura (daytime) in forest and preforest habitats and, Mogoplistidae sp3 (nighttime) in shrubland, that could explain the difference in community composition observed between invaded and non-invaded sites.

Finally, this approach is non-invasive, easy to manage on large temporal and spatial scales and more affordable - in terms of cost and field work effortsfor conservation programs. As demonstrated here, only a few days of soundscape recordings were necessary to describe the cricket calling community. If taxonomic knowledge is necessary to manually identify the calls in the recordings, additional research could focus on the application of automatic recognition techniques. Automatic identification challenges are expected to be reduced because (1) nighttime New Caledonian soundscapes of the dry season do not present extensive signal overlaps and (2) cricket stridulations are easy to identify by classic acoustic features including duration, echeme number, frequency range, and dominant frequency, thanks to previous taxonomic inventory practices.
Future research is needed to confirm the use of acoustic approaches for the early detection of the alien species arrival, evaluation of the invasion level and monitoring of restoration processes. Increasing the number of sampled sites would allow building a predictive model and to determine the invasion of a site based on the composition of its cricket community. In the present study, we considered invaded versus non-invaded sites, but we suspect that some native species may have a different degree of resistance to invasion (Holway et al. 2002) that, once described, could allow scientists and managers to estimate the level of invasion from the cricket calling community composition at a given time. Finally, the influence of the invasive strategy-movement in independent patches or along a coherent front lineon the presence of "refugium" patches for cricket species needs to be investigated. To illustrate this issue, several species-genera Koghiella and Agnotecous-living in micro-habitats exposed to foraging ants (leaf litter, bare soil) were recorded in invaded areas. Nevertheless, the high reduction of the number of stridulations of these species between non-invaded and invaded areas show the relative role of these 'refugia'. Another bias that needs to be investigated is related to the long-range calls of canopy species in close-by modalities such as the easily identified canopy species $C$. magnus living in forest and preforest that was recorded in shrublands sites, due to the long-distance propagation of its call.

Acknowledgements We would like to thank F. Rigault (IRD IMBE à Nouméa) and J-F. Julien (MNHN) who provided help for field work and $\mathrm{C}$. Desjonquères for her advice regarding GLMMs. We are grateful for the work of several undergraduate students, M. Aubert, J. Lansiaux, and L. Payandi. We are also grateful to E. Vidal (IRD Noumea) and B. C. Pijanowski (Purdue University) for logistical and financial support. We thank the two anonymous reviewers for their helpful and constructive comments. We would like to thank B. C. Pijanowski and G. Pignotti for their helpful comments to the manuscript. We thank the Province Sud Environment Office (DENV) for collecting permits (Decree 2155-2013/ARR/ DENV).

Funding This study was partly funded by a Ph.D. Grant, 'Bourse d'encouragement à la recherche universitaire', attributed to J. Anso by the Government of New Caledonia. This $\mathrm{Ph} . \mathrm{D}$. and associated field work was also supported by a funding attributed to J. Anso and H. Jourdan by the Agence Nationale de la Recherche (ANR) through the ERA-Net BiodivERsA Project (FFII, JE 288/7-1). The bioacoustic study was supported by a Grant from the Grand Observatoire du Pacifique Sud: AAP 
GOPS 2013/‘Bioacoustique des grillons de Nouvelle-Calédonie'. The laboratory procedures were realized through the three research programs: Action Transversale du Muséum (ATM) 'Biodiversité actuelle et fossile. Crises, stress, restaurations et panchronisme: le message systématique', ATM 'Barcode' and the Labex BCDIV (Diversités biologiques et culturelles) 'A diachronic study of biodiversity and a test of biogeographic scenarios in New Caledonia as based on field inventories of fossil and present-day insects'. The field work procedure was partly realized through the program: Action Transversale du Muséum (ATM) 'Formes possibles - Formes réalisées'. The analyses and redaction of the manuscript were partly funded by NSF RCN (\#1114945), Purdue University's Center for the Environment, Wright Forestry Fund of the Department of Forestry and Natural Resources at Purdue University, and the College of Agriculture at Purdue University.

\section{Compliance with ethical standards}

Conflict of interest The authors declare that they have no conflict of interest.

\section{References}

Anso J (2016) Maintien à long terme des communautés d'insectes forestiers dans un contexte de changement global: Réponses écologiques des communautés d'Orthoptères dans une succession forestière et face à la progression d'espèces invasives. Dissertation, Ph.D., Ecole Doctorale du Pacifique, Université de la Nouvelle-Calédonie, Nouméa

Anso J, Barrabé L, Desutter-Grandcolas L, Jourdan H, Grandcolas P, Dong J, Robillard T (2016a) Old lineage on an old island: Pixibinthus, a new cricket genus endemic to New Caledonia shed light on gryllid diversification in a hotspot of biodiversity. PLoS ONE 11:e0150920

Anso J, Jourdan H, Desutter-Grandcolas L (2016b) Crickets (Insecta, Orthoptera, Grylloidea) from southern New Caledonia, with descriptions of new taxa. Zootaxa 4124:1-92

Baselga A (2008) Determinants of species richness, endemism and turnover in European longhorn beetles. Ecography 31:263-271

Bates D, Maechler M, Bolker B, Walker S (2015) Fitting linear mixed-effects models using lme4. J Stat Softw 67:1-48

Berman M, Andersen AN, Hély C, Gaucherel C (2013) Overview of the distribution, habitat association and impact of exotic ants on native ant communities in New Caledonia. PLoS ONE 8:e67245

Boelman NT, Asner GP, Hart PJ, Martin RE (2007) Multitrophic invasion resistance in Hawaii: bioacoustics, field surveys, and airborne remote sensing. Ecol Appl 17:2137-2144

Bolker BM, Brooks ME, Clark CJ, Geange SW, Poulsen JR, Stevens MHH, White J-SS (2009) Generalized linear mixed models: a practical guide for ecology and evolution. Trends Ecol Evol 24:127-135

Bormpoudakis D, Sueur J, Pantis JD (2013) Spatial heterogeneity of ambient sound at the habitat type level: ecological implications and applications. Landsc Ecol 28:495-506

Chiarucci A, Bacaro G, Rocchini D, Fattorini L (2008) Discovering and rediscovering the sample-based rarefaction formula in the ecological literature. Community Ecol 9:121-123

Chintauan-Marquier IC, Legendre F, Hugel S, Robillard T, Grandcolas P, Nel A, Zuccon D, Desutter-Grandcolas L (2016) Laying the foundations of evolutionary and systematic studies in crickets (Insecta, Orthoptera): a multilocus phylogenetic analysis. Cladistics 32:54-81

De Cáceres M, Legendre P (2009) Associations between species and groups of sites: indices and statistical inference. Ecology 90:356-3574

De Cáceres M, Legendre P, Moretti M (2010) Improving indicator species analysis by combining groups of sites. Oikos 119:1674-1684

Desutter-Grandcolas L (1992) Les Phalangopsidae de Guyane française (Orthoptères, Grylloidea): systématique, éléments de phylogénie et de biologie. Bulletin du Muséum national d'Histoire naturelle, Paris 14:93-177

Desutter-Grandcolas L, Anso J, Jourdan H (2016) Crickets of New Caledonia (Insecta, Orthoptra, Grylloidea): a key to genera, with diagnoses of extant genera and descriptions of new taxa. Zoosystema 38:405-452

Diwakar S, Balakrishnan R (2007) The assemblage of acoustically communicating crickets of a tropical evergreen forest in southern India: call diversity and diel calling patterns. Int J Anim Sound Its Rec 16:113-135

Dufrêne M, Legendre P (1997) Species assemblages and indicator species: the need for a flexible asymetrical approach. Ecol Monogr 67:345-366

Ehrenfeld JG (2010) Ecosystem consequences of biological invasions. Annu Rev Ecol Evol Syst 41:59-80

Fartmann T, Krämer B, Stelzner F, Poniatowski D (2012) Orthoptera as ecological indicators for succession in steppe grassland. Ecol Ind 20:337-344

Frazer GW, Canham C, Lertzman K (1999) Gap light analyzer (GLA). Imaging software to extract canopy structure and gap light transmission indices from true-colour fisheye photographs. Users manual and program documentation. Version 2. Simon Fraser University, Burnaby

Gardiner T, Dover J (2008) Is microclimate important for Orthoptera in open landscapes? J Insect Conserv 12:705-709

Gasc A, Sueur J, Pavoine S, Pellens R, Grandcolas P (2013) Biodiversity sampling using a global acoustic approach: contrasting sites with microendemics in New Caledonia. PLoS ONE 8:e65311

Holway DA (1998) Loss of intraspecific aggression in the success of a widespread invasive social insect. Science 282:949-952

Holway DA, Lach L, Suarez AV, Tsutsui ND, Case TJ (2002) The Causes and Consequences of Ant Invasions. Annu Rev Ecol Syst 33:181-233 
Hulme PE (2006) Beyond control: wider implications for the management of biological invasions. J Appl Ecol 43:835-847

Jain M, Balakrishnan R (2011) Microhabitat selection in an assemblage of crickets (Orthoptera: Ensifera) of a tropical evergreen forest in Southern India. Insect Conserv Divers 4:152-158

Joo W, Gage SH, Kasten EP (2011) Analysis and interpretation of variability in soundscapes along an urban-rural gradient. Landsc Urban Plan 103:259-276

Jourdan H, Sadlier RA, Bauer AM (2001) Little fire ant invasion (Wasmannia auropunctata) as a threat to New Caledonian lizards: evidence from a sclerophyll forest (Hymenoptera: Formicidae). Sociobiology 38:283-299

Lach L, Hooper-Bui LM (2010) Consequences of ant invasion. In: Lach L, Parr CL, Abbott K (eds) Ant ecology. Oxford University Press, New York, pp 261-286

LaPolla JS, Otte D, Spearman LA (2000) Assessment of the effects of ants on Hawaiian crickets. J Orthopt Res 9:139-148

Le Breton J, Chazeau J, Jourdan H (2003) Immediate impacts of invasion by Wasmannia auropunctata (Hymenoptera: Formicidae) on native litter ant fauna in a New Caledonian rainforest. Austral Ecol 28:204-209

Legendre P, Legendre LF (2012) Numerical ecology, vol 24. Elsevier, Amsterdam

Lellouch L, Pavoine S, Jiguet F, Glotin H, Sueur J (2014) Monitoring temporal change of bird communities with dissimilarity acoustic indices. Methods Ecol Evol 5:495-505

Lowe S, Browne M, Boudjelas S, De Poorter M (2000) 100 of the World's worst invasive alien species. A selection from the global invasive species database. Published by the invasive species specialist group (ISSG) a specialist group of the species survival commission (SSC) of the world conservation union (IUCN), 12 p. First published as special lift-out in Aliens 12, December 2000. Updated and reprinted version: November 2004. http://www.issg.org/ booklet.pdf

Lubin YD (1984) Changes in the native fauna of the Galápagos Islands following invasion by the little red fire ant, Wasmannia auropunctata. Biol J Lin Soc 21:229-242

Minchin PR (1987) An evaluation of the relative robustness of techniques for ecological ordination. In: Prentice IC, van der Maarel E (eds) Theory and models in vegetation science, vol 8, Proceedings of symposium, Uppsala, pp 89-107

Myers N, Mittermeier RA, Mittermeier CG, Da Fonseca GA, Kent J (2000) Biodiversity hotspots for conservation priorities. Nature 403:853-858

Nakagawa S, Schielzeth H (2013) A general and simple method for obtaining R2 from generalized linear mixed-effects models. Methods Ecol Evol 4:133-142

Nattier R, Grandcolas P, Elias M, Desutter-Grandcolas L, Jourdan H, Couloux A, Robillard T (2012) Secondary sympatry caused by range expansion informs on the dynamics of microendemism in a biodiversity hotspot. PLoS ONE 7:e48047

Nischk F, Riede K (2001) Bioacoustics of two cloud forest ecosystems in Ecuador compared to a lowland rainforest with special emphasis on singing cricket species. In: Nieder
J, Barthlott W (eds) Epiphytes and canopy fauna of the Otongan rainforest (Ecuador), Results of the Bonn-Quito Epiphyte Project, Funded by the Volkswagen Foundation, vol 2, pp 217-242

Oksanen J, Blanchet FG, Kindt R, Legendre P, Minchin PR, O'Hara R, Simpson GL, Solymos P, Stevens M, Wagner H (2013) Package 'vegan'. community ecology package, version 2(9). https://CRAN.R-project.org/package=vegan

Otte D (1994) The crickets of Hawaii, origin, systematics and evolution. The Orthopterists' Society and The Academy of Natural Sciences of Philadelphia, Philadelphia

Otte D, Alexander RD (1983) The Australian crickets. Monogr Acad Nat Sci Phila 22:1-477

Pijanowski BC, Farina A, Gage SH, Dumyahn SL, Krause BL (2011) What is soundscape ecology? An introduction and overview of an emerging new science. Landsc Ecol 26:1213-1232

Qi J, Gage SH, Joo W, Napoletano B, Biswas S (2008) Soundscape characteristics of an environment: a new ecological indicator of ecosystem health. In: Ji W (ed) Wetland and water resource modeling and assessment. CRC Press, New York, pp 201-211

Riede K (1993) Monitoring biodiversity: analysis of Amazonian rainforest sounds. Ambio 22:546-548

Riede K (1997) Bioacoustic diversity and resource partitioning in tropical calling communities. In: Ulrich H (ed) Tropical biodiversity and systematics. Proceedings of the international symposium on biodiversity and systematics in tropical ecosystems, Bonn, pp 275-280

Robillard T, Grandcolas P, Desutter-Grandcolas L (2007) A shift toward harmonics for high-frequency calling shown with phylogenetic study of frequency spectra in Eneopterinae crickets (Orthoptera, Grylloidea, Eneopteridae). Can J Zool 85:1264-1274

Römer H (1993) Environmental and biological constraints for the evolution of long-range signalling and hearing in acoustic insects. Philos Trans R Soc Lond Ser B Biol Sci 340:179-185

Schirmel J, Mantilla-Contreras J, Blindow I, Fartmann T (2011) Impacts of succession and grass encroachment on heathland Orthoptera. J Insect Conserv 15:633-642

Simberloff D, Martin JL, Genovesi P, Maris V, Wardle DA, Aronson J, Courchamp F, Galil B, García-Berthou E, Pascal M, Pyšek P (2013) Impacts of biological invasions: what's what and the way forward. Trends Ecol Evol 28:58-66

Sueur J, Farina A (2015) Ecoacoustics: the ecological investigation and interpretation of environmental sound. Biosemiotics 8:493-502

Sueur J, Pavoine S, Hamerlynck O, Duvail S (2008) Rapid acoustic survey for biodiversity appraisal. PLoS ONE 3:e4065

Szinwelski N, Rosa CS, Schoereder JH, Mews CM, Sperber CF (2012) Effects of forest regeneration on crickets: evaluating environmental drivers in a 300 -year chronosequence. Int J Zool 2012:1-13

Towsey M, Jason W, Ian W, Paul R (2014) The use of acoustic indices to determine avian species richness in audiorecordings of the environment. Ecol Inf 21:110-119

Truskinger A, Cottman-Fields M, Johnson D, Roe P (2013) Rapid scanning of spectrograms for efficient identification 
of bioacoustic events in big data. In: IEEE (ed) IEEE 9th international conference on science, pp 270-277

Tucker D, Gage SH, Williamson I, Fuller S (2014) Linking ecological condition and the soundscape in fragmented Australian forests. Landsc Ecol 29:745-758
Vitousek PM, D’Antonio CM, Loope LL, Westbrooks R (1996) Biological invasions as global environmental change. Am Sci 84:468-478

Walker KL (2006) Impact of the little fire Ant, Wasmannia auropunctata, on native forest ants in Gabon. Biotropica 38:666-673 
Title: Cricket calling communities as an indicator of the invasive ant Wasmannia auropuncata in an insular biodiversity hotspot

Authors: Gasc $\mathrm{A}^{*, \dagger}$, Anso $\mathrm{J}^{\dagger}$, Sueur J, Jourdan $\mathrm{H}^{\S}$ and Desutter-Grandcolas $\mathrm{L}^{\S}$.

${ }^{\dagger}$ First authors for this publication

$\S$ Last authors for this publication

*Corresponding author

Purdue University, Department of Forestry and Natural Resources,

Center for Global Soundscapes,

203 South Martin Jischke Drive, B066 Mann Hall

West Lafayette, Indiana 47907, USA

Email. amandine.gasc@gmail.com

Resource 1: Description of the vegetation criteria defining the three habitat types

The "forest" type is a dense forest with large stems, a deep leaf litter entirely covering the ground, a closed canopy and a maximum vegetation height at $30 \mathrm{~m}$. The tree layer is composed of diverse dominant families, such as Araucariacea, Sapotacea, Myrtacae, and Proteacea. Palm trees, Pandanus and ferns dominate the shrub layer. The "preforest" type is similar to the "forest" type but with a lower vegetation height and plant species: the tree layer is characterized by an 
assemblage of Styphellia cymbulae, Hibbertia lucens, Alphitonia neaocaledonica, and Gymnostoma deplancheanum and the herbaceous layer is dominated by Lepidosperma perteres. The "shrubland" type is characterized by high bare ground expanse and absence of a continuous tree layer. Maximum vegetation height was about $3 \mathrm{~m}$ with an important herbaceous and shrub layers dominated by Sannantha sp., Eugenia sp., Alphitonia neocaledonica, Hibbertia lucens and H. pancheri. 
Title: Cricket calling communities as an indicator of the invasive ant Wasmannia auropuncata in an insular biodiversity hotspot

Authors: Gasc $\mathrm{A}^{*, \dagger}$, Anso $\mathrm{J}^{\dagger}$, Sueur J, Jourdan $\mathrm{H}^{\S}$ and Desutter-Grandcolas $\mathrm{L}^{\S}$.

${ }^{\dagger}$ First authors for this publication

$\S$ Last authors for this publication

*Corresponding author

Purdue University, Department of Forestry and Natural Resources,

Center for Global Soundscapes,

203 South Martin Jischke Drive, B066 Mann Hall

West Lafayette, Indiana 47907, USA

Email. amandine.gasc@gmail.com 
Resource 2: Table S1. Site descriptions.

\begin{tabular}{|c|c|c|c|c|c|}
\hline Site Code & Name & Habitat & Invaded (n/9) & Coordinates & Recording dates \\
\hline FO-BOI-W & Port Boisé & Forest & Yes (7/9) & $166.97343 \mathrm{E} / 22.34820 \mathrm{~S}$ & Oct. 23-Nov. 14 \\
\hline FO-FN-W & Foret Nord & Forest & Yes (9/9) & $166.92987 \mathrm{E} / 22.32372 \mathrm{~S}$ & Oct. 03-Oct. 23 \\
\hline FO-GK-W & Grand Kaori & Forest & Yes $(5 / 9)$ & $166.89601 \mathrm{E} / 22.28226 \mathrm{~S}$ & Oct. 02 -Oct. 30 \\
\hline FO-KA-W & Cap Ndua & Forest & Yes (9/9) & $166.91742 \mathrm{E} / 22.38645 \mathrm{~S}$ & Oct. 17-Nov. 14 \\
\hline FO-GK & Grand Kaori & Forest & No $(1 / 9)$ & $166.89674 \mathrm{E} / 22.28535 \mathrm{~S}$ & Oct. 02 -Oct. 10 \\
\hline FO-MOU & Mouirange & Forest & No $(0 / 9)$ & $166.68086 \mathrm{E} / 22.20416 \mathrm{~S}$ & Oct. 02 -Oct. 17 \\
\hline FO-PDP & Pic du pin & Forest & No $(0 / 9)$ & $166.82715 \mathrm{E} / 22.24680 \mathrm{~S}$ & Oct. 03-Oct. 17 \\
\hline FO-RIV & Rivière Blanche & Forest & No $(0 / 9)$ & $166.68643 \mathrm{E} / 22.15142 \mathrm{~S}$ & Oct. 04-Oct. 17 \\
\hline MA-BDS-W & Bois du Sud & Shrubland & Yes (7/9) & $166.76093 \mathrm{E} / 22.17321 \mathrm{~S}$ & Nov. 20-Dec 16 \\
\hline MA-GKE-W & Grand Kaori Ext. & Shrubland & Yes (9/9) & $166.86960 \mathrm{E} / 22.27110 \mathrm{~S}$ & Oct. 23-Nov. 14 \\
\hline MA-KA-W & Cap Ndua & Shrubland & Yes (8/9) & $166.93486 \mathrm{E} / 22.32278 \mathrm{~S}$ & Oct. 17-Nov. 14 \\
\hline MA-RIV-W & Rivière Blanche & Shrubland & Yes (6/9) & $166.70937 \mathrm{E} / 22.13480 \mathrm{~S}$ & Oct. 17-Nov. 07 \\
\hline MA-MAD & Madelaine & Shrubland & No $(0 / 9)$ & $166.85268 \mathrm{E} / 22.23568 \mathrm{~S}$ & Oct. 17-Nov. 14 \\
\hline MA-FN & Forest Nord & Shrubland & No $(2 / 9)$ & $166.93501 \mathrm{E} / 22.32277 \mathrm{~S}$ & Oct. 23-Nov. 14 \\
\hline MA-GK & Grand Kaori & Shrubland & No $(2 / 9)$ & $166.89436 \mathrm{E} / 22.28460 \mathrm{~S}$ & Oct. 02-Oct. 17 \\
\hline MA-RIV & Rivière Blanche & Shrubland & No $(3 / 9)$ & $166.70796 \mathrm{E} / 22.13625 \mathrm{~S}$ & Oct. 04-Oct. 17 \\
\hline PA-FN-W & Foret Nord & Preforest & Yes (9/9) & $166.93361 \mathrm{E} / 22.32385 \mathrm{~S}$ & Oct. 03 -Oct. 23 \\
\hline PA-GK-W & Grand Kaori & Preforest & Yes (7/9) & $166.89510 \mathrm{E} / 22.28345 \mathrm{~S}$ & Oct. 02 -Oct. 30 \\
\hline PA-KA-W & Cap Ndua & Preforest & Yes (9/9) & $166.91881 \mathrm{E} / 22.38629 \mathrm{~S}$ & Oct. 17-Nov. 14 \\
\hline PA-PRO-W & Prony & Preforest & Yes (8/9) & $166.80473 \mathrm{E} / 22.31902 \mathrm{~S}$ & Oct. 23-Nov. 15 \\
\hline PA-FN & Forêt Nord & Preforest & No (4/9) & $166.93134 \mathrm{E} / 22.32259 \mathrm{~S}$ & Oct.03-Oct. 23 \\
\hline PA-GK & Grand Kaori & Preforest & No $(0 / 9)$ & $166.89383 \mathrm{E} / 22.28000 \mathrm{~S}$ & Oct.02-Oct. 20 \\
\hline PA-PEP & Pépinière & Preforest & No $(0 / 9)$ & $166.96355 \mathrm{E} / 22.27103 \mathrm{~S}$ & Oct. 02 -Oct. 17 \\
\hline PA-RIV & Rivière Blanche & Preforest & No $(0 / 9)$ & $166.68033 \mathrm{E} / 22.15280 \mathrm{~S}$ & Oct. 04-Oct. 17 \\
\hline
\end{tabular}

Sites are considered as Invaded if $\mathrm{n}<5$ with $\mathrm{n}$ the number of observation of $W$. auropunctata around the recorder. 
Title: Cricket calling communities as an indicator of the invasive ant Wasmannia auropuncata in an insular biodiversity hotspot

Authors: Gasc $\mathrm{A}^{*, \dagger}$, Anso $\mathrm{J}^{\dagger}$, Sueur J, Jourdan $\mathrm{H}^{\S}$ and Desutter-Grandcolas $\mathrm{L}^{\S}$.

${ }^{\dagger}$ First authors for this publication

$\S$ Last authors for this publication

*Corresponding author

Purdue University, Department of Forestry and Natural Resources,

Center for Global Soundscapes,

203 South Martin Jischke Drive, B066 Mann Hall

West Lafayette, Indiana 47907, USA

Email. amandine.gasc@gmail.com 


\section{Resource 3:}

Table S2. Summary of acoustic observations from soundscape recordings for each cricket species and on non-invaded and invaded sites separately.

\begin{tabular}{|c|c|c|c|c|c|c|}
\hline & Non-invad & & & Invaded sit & & \\
\hline Species & Rec. num. & Call num. & Av. call per rec. (sd.) & Rec. num. & Call num. & Av. call per rec. (sd.) \\
\hline Agnotecous azurensis & 381 & 2851 & $7.48(5.43)$ & 64 & 309 & $4.83(3.12)$ \\
\hline Agnotecous clarus & 88 & 630 & $7.16(4.04)$ & 0 & 0 & 0 \\
\hline Agnotecous meridionalis & 21 & 91 & $4.33(2.85)$ & 0 & 0 & 0 \\
\hline Archenopterus bouensis & 342 & 5648 & $16.51(12.26)$ & 9 & 42 & $4.67(6.26)$ \\
\hline Bullita fusca & 330 & 28952 & $87.73(62.50)$ & 0 & 0 & 0 \\
\hline Bullita mouirangensis & 60 & 5106 & $85.1(26.42)$ & 0 & 0 & 0 \\
\hline Bullita obscura & 67 & 5634 & $84.09(49.83)$ & 0 & 0 & 0 \\
\hline Calcirtus magnus & 421 & 13832 & $32.86(35.27)$ & 360 & 10787 & $29.96(31.97)$ \\
\hline Koghiella flammea & 312 & 19702 & $63.15(45.29)$ & 32 & 1115 & $34.84(26.25)$ \\
\hline Koghiella nigris & 211 & 2463 & $11.67(9.65)$ & 19 & 390 & $20.53(25.67)$ \\
\hline Trigonidiinae sp & 40 & 6272 & $156.8(53)$ & 47 & 4002 & $85.15(36.88)$ \\
\hline Mogoplistidae sp1 & 205 & 11115 & $54.22(51.39)$ & 67 & 3758 & $56.09(38.20)$ \\
\hline Mogoplistidae sp2 & 221 & 4970 & $22.49(20.04)$ & 77 & 1123 & $14.58(12.68)$ \\
\hline Mogoplistidae sp3 & 85 & 3346 & $39.36(33.12)$ & 0 & 0 & 0 \\
\hline Mogoplistidae sp7 & 74 & 2775 & $37.5(39.10)$ & 56 & 2807 & $50.125(33.63)$ \\
\hline Notosciobia affinis paranola & 100 & 8153 & $81.53(57.61)$ & 51 & 1163 & $22.80(23.02)$ \\
\hline Notosciobia minoris & 1 & 45 & 45 & 61 & 6870 & $112.62(57.94)$ \\
\hline Notosciobia $\mathrm{sp} 1$ & 3 & 1006 & $335.33(56.13)$ & 0 & 0 & 0 \\
\hline Pseudotrigonidium caledonica & 71 & 580 & $8.17(4.21)$ & 0 & 0 & 0 \\
\hline
\end{tabular}

"Rec". calls for "recording", "num." for "number", "av." for "average", and "sd." for "standard deviation" 


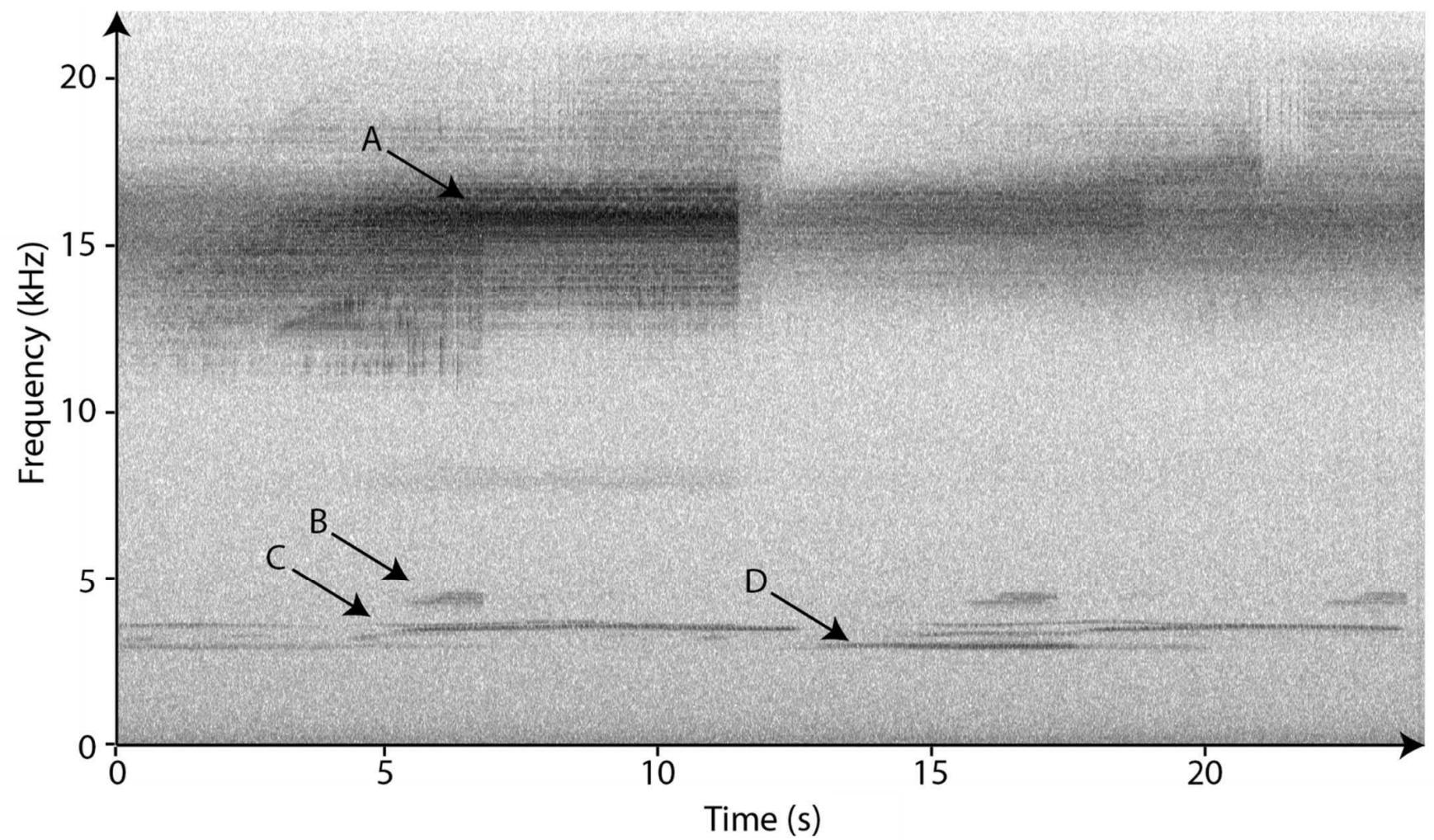

Fig. S1. Spectrogram of one recording from the non-invaded forest site "Pic du Pin" by night at 9 p.m. Four species were calling here: A calls for Agnotecous azurensis (six calls), B for Koghiella nigris (three calls), C for Archenopterus bouensis (four calls), and D for Pseudotrigonidium caledonica (two calls). 
Title: Cricket calling communities as an indicator of the invasive ant Wasmannia auropuncata in an insular biodiversity hotspot

Authors: Gasc $\mathrm{A}^{*, \dagger}$, Anso $\mathrm{J}^{\dagger}$, Sueur J, Jourdan $\mathrm{H}^{\S}$ and Desutter-Grandcolas $\mathrm{L}^{\S}$.

${ }^{\dagger}$ First authors for this publication

$\S$ Last authors for this publication

*Corresponding author

Purdue University, Department of Forestry and Natural Resources,

Center for Global Soundscapes,

203 South Martin Jischke Drive, B066 Mann Hall

West Lafayette, Indiana 47907, USA

Email. amandine.gasc@gmail.com 
Resource 4: Information concerning the models.

\section{Model information}

The description of the models follows the recommendations given by Nakagawa et al. (2013). This description is complemented here by the validation steps presented in the materials and methods.

\section{1) Mathematical description of the models}

\section{Formulae for the model 1:}

Distribution-specific variance: $\ln \left(1 / \exp \left(\beta_{0}\right)+1\right)$

$$
\begin{aligned}
& y_{i j k l}=\operatorname{Poisson}\left(\mu_{i j k l}\right) \\
& \operatorname{link}\left(\mu_{i j k l}\right)=\beta_{0}+\sum_{h=1}^{2} \beta_{h} S_{h i j k l}+\alpha_{j}+\delta_{k}+\gamma_{l}+\varepsilon_{i j k l}
\end{aligned}
$$

where $y_{i j k l}$ is the $i$ th count of species at the jth site at the $k$ th date and the lth time, $\mu_{i j k l}$ is the underlying (latent) mean for the $i$ th count of species at the $j$ th site at the $k$ th date and the $l$ th time, $\beta_{0}$ is the intercept, $\beta_{h}$ is the slope of the $h$ th predictor $(h=1$ represent the invasion factor and $h=2$ represent the habitat factor), $\mathrm{X}_{\text {hijk }}$ is the $i$ th values $j$ th site at the $k$ th date and the $l$ th time for the $h$ th predictor, $\alpha_{j}$ is the site specific effect following a normal distribution of mean 0 and variance $\sigma_{\alpha}, \delta_{k}$ id the date specific effect following a normal distribution of mean 0 and variance $\sigma_{\delta}, \gamma_{l}$ is the time specific effect following a normal distribution of mean 0 and variance $\sigma_{\gamma}$ and $\varepsilon_{i j k l}$ is the residual following a normal distribution of mean 0 and variance $\sigma_{\varepsilon}$. This model has been implemented in R as follows: glmer(SpeciesNumber $\sim$ invasion + habitat + $(1 \mid$ site $)+(1 \mid$ date $)+(1 \mid$ time $)$, family=poisson $)$ 


\section{Formulae for the $R^{2}$ for Poisson model 1:}

Given $\sigma_{f 1}^{2}$, the variance of the fixed effect components of the model 1, we calculated the marginal $R^{2}\left(R_{\mathrm{m} 1}^{2}\right)$ and the conditional $R^{2}\left(R_{\mathrm{c} 1}^{2}\right)$ of the model 1 as follows:

$$
\begin{aligned}
& \sigma_{f 1}^{2}=\operatorname{var}\left(\sum_{h=1}^{2} \beta_{h} S_{h i j k l}\right) \\
& R_{\mathrm{m} 1}^{2}=\frac{\sigma_{f 1}^{2}}{\sigma_{f}^{2}+\sigma_{\alpha}^{2}+\sigma_{\delta}^{2}+\sigma_{\gamma}^{2}+\sigma_{\varepsilon}^{2}+\ln \left(1 / \exp \left(\beta_{0}+1\right)\right)} \\
& R_{\mathrm{c} 1}^{2}=\frac{\sigma_{f 1}^{2}+\sigma_{\alpha}^{2}+\sigma_{\delta}^{2}+\sigma_{\gamma}^{2}}{\sigma_{f 1}^{2}+\sigma_{\alpha}^{2}+\sigma_{\delta}^{2}+\sigma_{\gamma}^{2}+\sigma_{\varepsilon}^{2}+\ln \left(1 / \exp \left(\beta_{0}+1\right)\right)}
\end{aligned}
$$

\section{Formulae for the model 2:}

Link function: $\log$ link

Distribution-specific variance: $\ln \left(1 / \exp \left(\lambda_{0}\right)+1\right)$

$$
\begin{aligned}
& z_{i j k}=\operatorname{Poisson}\left(\kappa_{i j k}\right) \\
& \operatorname{link}\left(\kappa_{i j k}\right)=\lambda_{0}+\sum_{h=1}^{2} \lambda_{h} C_{h i j k}+a_{j}+b_{k}+c_{i j k}
\end{aligned}
$$

where $z_{i j k l}$ is the $i$ th count of calls at the $j$ th site at the $k$ th date, $\kappa_{i j k l}$ is the underlying (latent) mean for the ith count of calls at the $j$ th site at the $k$ th date, $\lambda_{0}$ is the intercept, $\lambda_{h}$ is the slope of the $h$ th predictor ( $h=1$ represent the invasion factor and $h=2$ represent the habitat factor), $C_{h i j k}$ is the $i$ th value at the jth site at the $k$ th date for the $h$ th predictor, $a_{j}$ is the site specific effect following a normal distribution of mean 0 and variance $\sigma_{a}, b_{k}$ id the date specific effect following a normal distribution of mean 0 and variance $\sigma_{b}$ and $c_{i j k}$ is the residual following a normal distribution of mean 0 and variance $\sigma_{c}$. This model has been implemented in $\mathrm{R}$ as follows: glmer (CallNumber $\sim$ invasion + habitat $+(1 \mid$ site $)+(1 \mid$ date $)$, family=poisson $)$ 


\section{Formulae for the $R^{2}$ for Poisson model 2:}

Given $\sigma_{f 2}^{2}$ the variance of the fixed effect components of the model 2, we calculated the marginal $R^{2}\left(R_{\mathrm{m} 2}^{2}\right)$ and the conditional $R^{2}\left(R_{\mathrm{c} 2}^{2}\right)$ of the model 2 as follows:

$$
\begin{aligned}
& \sigma_{f 2}^{2}=\operatorname{var}\left(\sum_{h=1}^{2} \lambda_{h} C_{h i j k}\right) \\
& R_{\mathrm{m} 2}^{2}=\frac{\sigma_{f 2}^{2}}{\sigma_{f 2}^{2}+\sigma_{a}^{2}+\sigma_{b}^{2}+\sigma_{c}^{2}+\ln \left(1 / \exp \left(\lambda_{0}+1\right)\right)} \\
& R_{\mathrm{c} 2}^{2}=\frac{\sigma_{f 2}^{2}+\sigma_{a}^{2}+\sigma_{b}^{2}}{\sigma_{f 2}^{2}+\sigma_{a}^{2}+\sigma_{b}^{2}+\sigma_{c}^{2}+\ln \left(1 / \exp \left(\lambda_{0}+1\right)\right)}
\end{aligned}
$$

\section{2) Results and validations of the models}

The results of the models are available in the Table S3. For each model, we tested for deviation of the residuals from 1) linearity, homoscedasticity and normality by visual inspection of the relationship of residuals against fitted values and the quantile-quantile plot of residuals, and 2) the absence of collinearity between the fixed effects by looking at the Generalized Variation Inflation Factor (Fox and Monette, 1992) calculated with the function vif from the R car package (Fox and Weisberg, 2011). Time seemed to have a negative effect on the linearity of the residuals of the model 2 that has been corrected by removing this factor of the model. The Generalized Variation Inflation Factor looking at the absence of the collinearity between the fixed effects is presented in the Table S4. Validation of linearity, homoscedasticity and normality of the residuals can be visual inspected by looking at the plots of the residuals against fitted values and the Quantile-Quantile plot of residuals presented in the Figure S2. 
Table S3: Results of the Generalized mixed models.

\begin{tabular}{llll} 
& \multicolumn{1}{l}{ Model1 } & Model2 \\
\hline Fixed effects & Estimates (SD) & Estimates (SD) \\
\hline & Intercept & $1.4633(0.3044)$ & $4.7076(0.5684)$ \\
& Invasion (With) & $-1.3822(0.2827)$ & $-1.6887(0.5398)$ \\
& Habitat (Shurbland) & $-1.1154(0.3474)$ & $-1.5645(0.6543)$ \\
& Habitat (Paraforest) & $-0.4847(0.3416)$ & $-0.5598(0.6345)$ \\
\hline Random effects & Variance (SD) & Variance (SD) \\
\hline & Site & 0.4541680 .6739 & - \\
& Date & $0.001(0.0286)$ & $0.586(0.7653)$ \\
& Time & $0.1506(0.388)$ & $1.628(1.2760)$ \\
\hline $\mathrm{R}^{2} \mathrm{~m}$ & & 0.3873315 & 0.5370056 \\
$\mathrm{R}^{2} \mathrm{c}$ & & 0.6208671 & 0.8607849 \\
$\mathrm{AIC}$ & 3817.386 & 57810.73 \\
$\mathrm{BIC}$ & 3838.475 & 57826.54
\end{tabular}

"SD" calls for standard deviation

Table S4: Generalized Variation Inflation Factor (GVIF) results, similar for both models.

\begin{tabular}{llll} 
& GVIF & Df & $\operatorname{GVIF}^{(1 /(2 * \mathrm{Df}))}$ \\
\hline Envahis & 1 & 1 & 1 \\
Habitat & 1 & 2 & 1 \\
\hline
\end{tabular}

\section{Literature Cited}

Fox J, Monette G. 1992. Generalized collinearity diagnostics. Journal of the American Statistical Association 87:178-183.

Fox J, Weisberg S. 2011. An R Companion to Applied Regression, second ed. Sage, Thousand Oaks CA. 
Model 1
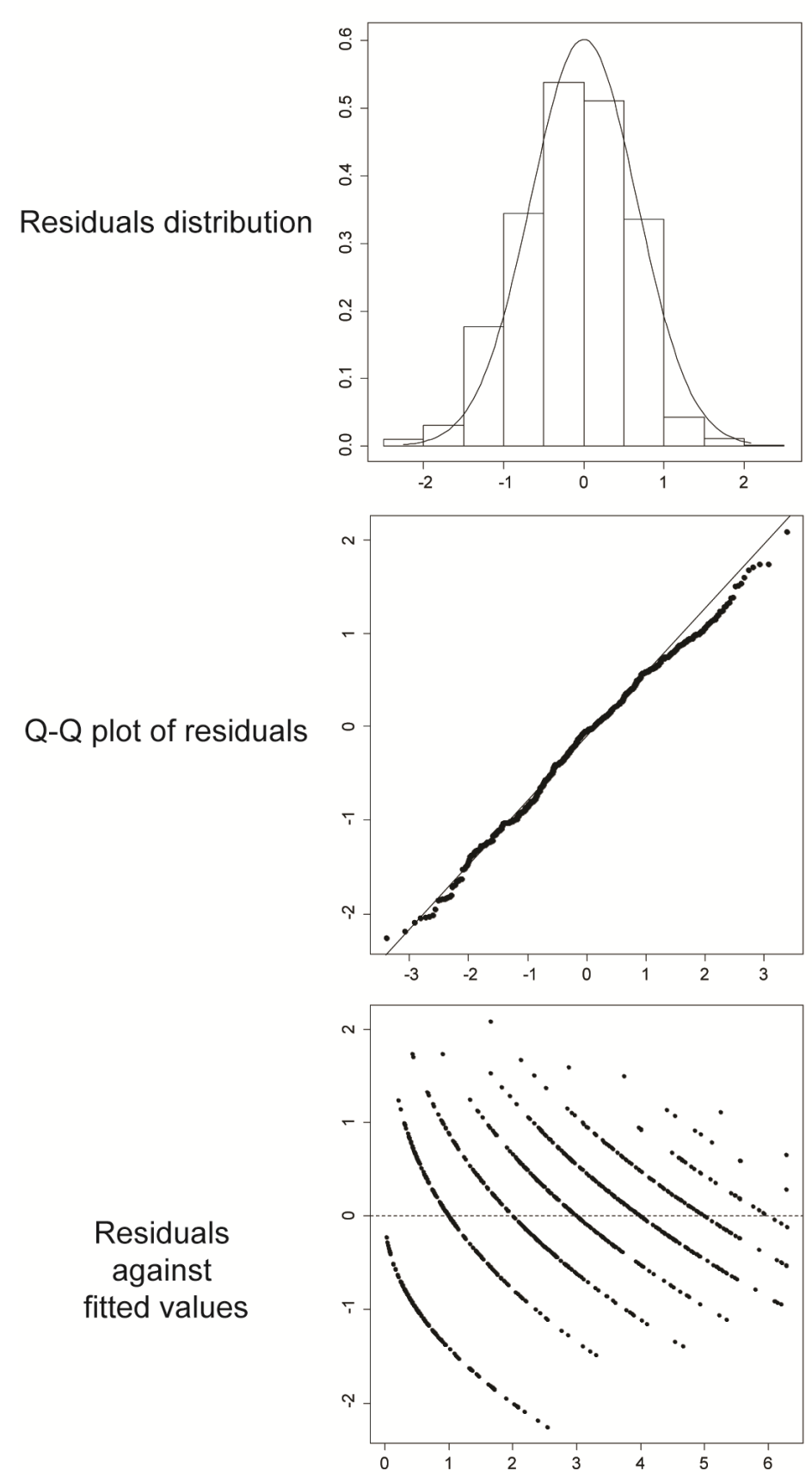

Model 2
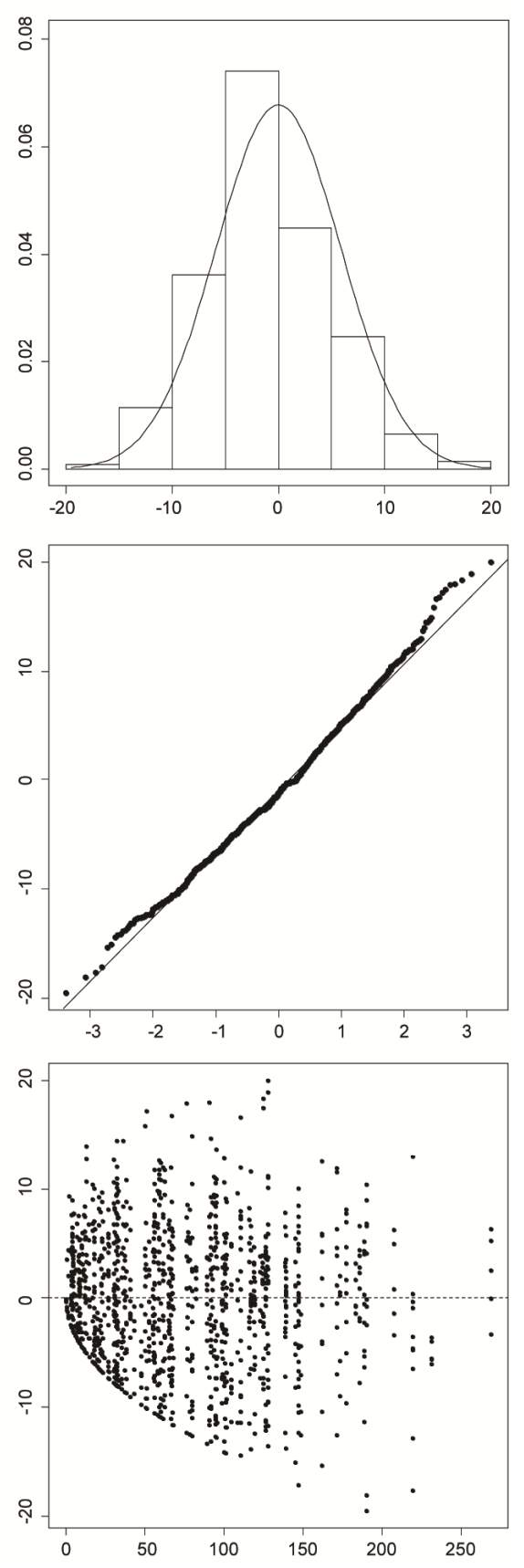

Figure S2. Three graphics for the inspection of the residuals of the models 1 and 2: the histogram of the residuals, the Quantile-Quantile plot of residuals and the plot of the residuals against the fitted values. 